\title{
VEGF directly suppresses activation of $T$ cells from ascites secondary to ovarian cancer via VEGF receptor type 2
}

\author{
NG Gavalas', M Tsiatas', O Tsitsilonis ${ }^{2}$, E Politi $^{3}, \mathrm{~K}$ loannou ${ }^{2}$, AC Ziogas' $^{\prime}$ A Rodolakis ${ }^{4}, \mathrm{G} \mathrm{Vlahos}{ }^{4}$, \\ N Thomakos ${ }^{4}$, D Haidopoulos ${ }^{4}$, E Terpos', A Antsaklis ${ }^{4}$, MA Dimopoulos' and A Bamias ${ }^{*}, 1$ \\ 'Department of Clinical Therapeutics, Medical School, University of Athens, Alexandra Hospital, 80 Vas. Sofias Avenue, 11528 Athens, Greece; \\ ${ }^{2}$ Department of Animal and Human Physiology, Faculty of Biology, University of Athens, Panepistimiopolis, 15784 Athens, Greece; ${ }^{3}$ Cytopathology \\ Department, Medical School, University of Athens, Aretaieion Hospital, 76 Vas. Sofias Avenue, 11528 Athens, Greece; ${ }^{4}$ Department of Obstetrics and \\ Gynaecology, Medical School, University of Athens, Alexandra Hospital, 80 Vas. Sofias Avenue, 11528 Athens, Greece
}

BACKGROUND: Vascular endothelial growth factor action in tumour angiogenesis is well characterised; nevertheless, it functions as a key element in the promotion of the immune system's evasion by tumours. We sought to investigate the possible direct effect of VEGF on T-cell activation and through which type of VEGF receptor it exerts this effect on cells isolated from ovarian cancer patients' ascites.

METHODS: T cells isolated from the ascites of ovarian cancer patients were cultured with anti-CD3 and IL-2, with or without VEGF for 14 days and the number of viable $T$ cells was counted. Cytotoxic activity of cultured $T$ cells and expression of VEGF receptor-2 (VEGFR-2), was assayed.

RESULTS: The addition of VEGF in cultures significantly reduced the number and proliferation rate of $T$ cells in a dose-dependent manner and $\mathrm{CD}^{+}{ }^{+} \mathrm{T}$ cells expressed VEGFR-2 on their surface upon activation. Experiments with specific anti-VEGFR-2 antibodies revealed that the direct suppressive effect of VEGF on T-cell proliferation is mediated by VEGFR-2. We also showed that VEGF significantly reduced the cytotoxic activity of $T$ cells.

CONCLUSION: Our study showed that ascites-derived T cells secrete VEGF and express VEGFR-2 upon activation. Vascular endothelial growth factor directly suppresses T-cell activation via VEGFR-2.

British Journal of Cancer (2012) 107, 1869-1875. doi:10.1038/bjc.2012.468 www.bjcancer.com

(C) 2012 Cancer Research UK

Keywords: VEGF; VEGFR-2; T cells; ovarian cancer; immune suppression

Angiogenesis consists a fundamental mechanism required for a number of pathophysiological processes, among others tumour growth. It constitutes a dynamic process and a high number of proangiogenic and antiangiogenic molecules have critical roles in regulating angiogenesis. In response to stimuli, such as hypoxia, oxidative stress and acidosis, several proangiogenic factors are released from endothelial, stromal and tumour cells into the microenvironment (Gasparini et al, 2005). Over 30 angiogenic factors have been identified and reported to have important roles in angiogenesis, with the dominant growth factor controlling this process being the vascular endothelial growth factor (VEGF) (Ribatti and Vacca, 2008). Vascular endothelial growth factor is a dimeric polypeptide with molecular weight ranging from 35 to $45 \mathrm{kDa}$. Vascular endothelial growth factor refers to a family of growth factors, comprising seven different proteins, VEGF-A, VEGF-B, VEGF-C, VEGF-D, VEGF-E and placental growth factor isoforms 1 and 2 (Lyons et al, 2010). Direct actions of VEGF include stimulation of endothelial mitogenesis, promotion of endothelial survival/control of vascular permeability and promotion of cell migration (Zucker et al, 1998; Tam et al, 2006).

*Correspondence: Dr A Bamias; E-mail: abamias@med.uoa.gr Received 23 July 2012; revised 17 September 2012; accepted 20 September 2012
Moreover, it has been recently proposed that VEGF may have a direct effect on tumour cell growth (Tam et al, 2006).

Vascular endothelial growth factor molecules exert their angiogenic effects by binding to specific VEGF receptors (VEGFR). Vascular endothelial growth factor ligands bind to three primary receptors, namely VEGFR-1 and VEGFR-2 associated with angiogenesis, and VEGFR-3, which is associated with lymphangiogenesis (Zucker et al, 1998; Ferrara, 2004; Tam et al, 2006; Lyons et al, 2010; Waldner et al, 2010). Vascular endothelial growth factor receptor-2 (Flk-1/KDR) is responsible for the majority of the downstream angiogenic effects of VEGF, including microvascular permeability, endothelial cell proliferation, invasion, migration and survival (Bergers and Benjamin, 2003). Recent data suggest that VEGF contributes to tumour growth not only by promoting angiogenesis but also by an indirect mechanism of regulation of $\mathrm{T}$ cells involved in the immune response against the tumour (Bergers and Benjamin, 2003; Hicklin and Ellis, 2005; Mimura et al, 2007; Zindl and Chaplin, 2010). More specifically, VEGF has been demonstrated in vitro to hinder the functional maturation of dendritic cells from their hematopoietic progenitors (Gabrilovich et al, 1996). In addition, VEGF, at pathophysiological concentrations, interferes with the thymic development of $\mathrm{T}$ cells from early hematopoietic progenitor cells (Ohm et al, 2003). T cells are pivotal in the induction and progression of the anti-tumour immune reaction in many types of cancer, including ovarian 
carcinomas and cancer patients demonstrate impaired T-cell functions; however, the direct effect of VEGF on activation and proliferation of $\mathrm{T}$ cells present in ovarian cancer patients' ascites and the means via which this effect is mediated, have not been addressed.

We have previously demonstrated that the levels of VEGF in the ascitic fluid was an independent adverse prognostic factor in a cohort of 65 patients with advanced ovarian cancer and were inversely correlated with immunologically important T-cell subpopulations, such as $\mathrm{CD}^{+}{ }^{+} \mathrm{CD}_{6}{ }^{+}$NK-like T cells (Bamias et al, 2008). These results were indicative of an additional immunosuppressive function exerted by this factor. We have also demonstrated that VEGF directly suppresses the activation of peripheral blood T cells from ovarian cancer patients and healthy individuals, and that this effect is exerted specifically via VEGFR-2 (Ziogas et al, 2012). Nevertheless, the concentration of VEGF necessary to suppress immune cell functions in vitro was considerably higher than that determined in the blood of ovarian cancer patients and rather resembled VEGF levels recorded in their ascites (Ziogas et al, 2012). This indicates that VEGF-mediated immunosuppression is more likely to occur in the peritoneal cavity, which is an environment particularly enriched in cancer cells.

Based on the aforementioned background, we studied the possible direct effect of VEGF on T cells isolated from the ascites of ovarian cancer patients. We also studied the expression of VEGFRs on these T cells and the effect of VEGF on their cytotoxic activity against cancer cell lines and autologous cancer cells.

\section{MATERIALS AND METHODS}

\section{Cell isolation and culture}

The study protocol had the appropriate IRB approval and informed consent was given by all subjects for the collection of ascitic fluids. No patient had undergone chemotherapy before sample collection. Ascitic fluids were collected from ovarian cancer patients in heparinised tubes via abdominal paracentesis as described (Bamias et al, 2007) and centrifuged to pellet tumour and mononuclear cells. Separation of tumour cells from the mononuclear cells was performed by centrifugation on $75-100 \%$ discontinuous Ficoll-Histopaque (Sigma Chemical Co., St Lewis, MO, USA) density gradient for $30 \mathrm{~min}$ at $400 \mathrm{~g}$ at $16^{\circ} \mathrm{C}$. Layers of tumour and mononuclear cells were collected and washed twice in Hank's Balanced Salt Solution (GIBCO BRL, Grand Island, NY, USA). Cells were cultured as previously described (Ziogas et al, 2012). All samples processed, had cell viability over $80 \%$. Tumour cells were cryopreserved in $90 \%$ fetal bovine serum (GIBCO BRL), $10 \%$ dimethyl-sulfoxide (Sigma Chemical Co.). Mononuclear cells were resuspended in culture medium consisting of RPMI 1640 Glutamax (GIBCO BRL), supplemented with $10 \%$ fetal bovine serum, $50 \mu \mathrm{g} \mathrm{ml}^{-1}$ garamycin (GIBCO BRL) and $10 \mathrm{~mm}$ Hepes (GIBCO BRL), at a final concentration of $5 \times 10^{6}$ cells per $\mathrm{ml}$ and incubated for $2 \mathrm{~h}$ at $37^{\circ} \mathrm{C}, 5 \% \mathrm{CO}_{2}$ in $100-\mathrm{cm}^{2}$ tissue culture plates (Greiner Bio-one, Frickenhausen, Germany) for monocytes and other non-CD3 ${ }^{+}$cells to adhere to the plastic surface (non-T-cell depletion data is provided in Supplementary Information). For comparison, depletion of non-T cells was also performed using anti-CD3 microbeads (Miltenyi Biotec, Boston, MA, USA), an established method providing high-purity cell populations. The successful depletion of non-CD3 cells was confirmed by immunohistochemistry (see Supplementary Information). Non-adherent cells were aspirated, resuspended in culture medium at a final concentration of $1 \times 10^{6}$ per $\mathrm{ml}$ and $2 \mathrm{ml}$ aliquots were plated in 24-well plates (Greiner Bio-one). Human anti-CD3 monoclonal antibody (mAb; R\&D Systems, Minneapolis, MN, USA) at a final concentration of $25 \mathrm{ng} \mathrm{ml}^{-1}$ and recombinant human interleukin-2 (rhIL-2; R\&D Systems) at a final concentration of $150 \mathrm{IU} \mathrm{ml}^{-1}$ were added on day 1 of culture to induce T-cell proliferation. Cultures were supplemented with rhIL-2 every 3-4 days, for a total of 14 days. To study the dose-dependent effect of VEGF on T-cell proliferation, rVEGF (R\&D Systems) was added in cultures at 3-4 day intervals, at the concentrations indicated in the respective figures. Each VEFG concentration was tested in triplicate wells plated with the same $\mathrm{T}$ cells and mean values were used for analyses. Cultures were incubated at $37^{\circ} \mathrm{C}$, $5 \% \mathrm{CO}_{2}$. Cell expansion in cultures was assessed using an improved Neubauer hemocytometer. Cell proliferation was tested using the ${ }^{3} \mathrm{H}$-thymidine incorporation assay according to Ziogas et al (2012) and Georgaki et al (2009). To block VEGFR-2 activity, $1 \mu \mathrm{g} \mathrm{ml}^{-1}$ of neutralising anti-VEGFR-2 mAb (R\&D Systems) was added in cultures on days $0,1,3$ and consequently every 3 days.

\section{Flow cytometric analysis}

Cultured $\mathrm{T}$ cells were analysed for surface expression of VEGFRs on days 0,7 and 14, using fluorescence activated cell scanning, as previously described (Bamias et al, 2008). Briefly, $10^{6}$ cells were incubated with mouse anti-human mAbs against CD3, VEGFR-1, VEGFR-2, VEGFR-3 or IgG $_{1}$ antibodies used as isotype controls (BD Pharmingen, San Jose, CA, USA) at $4{ }^{\circ} \mathrm{C}$ for $30 \mathrm{~min}$. Cells were washed twice in washing buffer (PBS containing $0.5 \%$ fetal bovine serum and $0.01 \%$ sodium azide), fixed with CellFix solution (BD Pharmingen) and subsequent analysis was performed on a three-colour fluorescence FACSCalibur cytometer using CellQuest software (Becton-Dickinson, San Jose, CA, USA). At least 10000 gated events per condition were analysed. Specific subpopulations of $\mathrm{T}$ cells were identified using anti-CD4, CD8, CD56 and CD25 mAbs, as previously described (Bamias et al, 2007, 2008).

\section{Enzyme-linked immunosorbent assay (ELISA) determination of human VEGF}

Soluble VEGF levels in the initial ascitic fluid and in culture supernatants were determined by standard ELISA methods, using a VEGF detection kit in accordance to the manufacturer's instructions (R\&D Systems).

\section{Immunocytochemistry}

Immunocytochemistry experiments were performed as described (Ziogas et al, 2012). Briefly, cytological specimens were prepared in a cytocentrifuge (cytospin 4, ThermoShandon, Waltham, MA, USA) and placed in ethanol for $30 \mathrm{~min}$. Immunocytochemical studies were performed using the automated Ventana immunostainer (Ventana NexES; Ventana Medical Systems Inc., Tuscon, AZ, USA), using the iVIEW DAB detection kit (Ventana). Samples were incubated with either Flt-1/VEGFR-1 rabbit polyclonal Ab (Neomarkers, Lab Vision Corporation, Waltham, MA, USA) (dilution $1: 25$ ) or Flk-1/VEGFR-2 mouse mAb (Santa Cruz Biotechnology, Santa Cruz, CA, USA) (dilution 1:25), anti-CD3 mAb (DakoCytomation, Glostrup, Denmark), anti-calretinin mAb (Invitrogen, Carlsbad, CA, USA), plus relevant positive and negative controls. The specific antibody was localised by a universal antirabbit and anti-mouse secondary IgG-biotinylated antibody cocktail followed by a streptavidin-peroxidase conjugate (incubation time $8 \mathrm{~min}$ ) and visualised as a brown stain with diaminobenzidine (DAB) chromogen (incubation time $8 \mathrm{~min}$ ) with copper sulphate enhancement (incubation time $4 \mathrm{~min}$ ). All incubations were performed at a standardised temperature of $37^{\circ} \mathrm{C}$. Following the automated staining process, subsequent to counterstaining with hematoxylin (incubation time $4 \mathrm{~min}$ ), the slides were rinsed in tap water, dehydrated and coverslipped.

\section{Western blotting}

Monocyte-depleted ascitic lymphocytes were grown with or without VEGF, cell lysates were prepared using $10 \times 10^{6}$ cells per 
preparation and subjected to western blotting as described before (Sambrook et al, 1989; Ziogas et al, 2012). Briefly, $50 \mu \mathrm{g}$ of total protein from each preparation was mixed with SDS-PAGE reducing buffer (Sigma Aldrich Ltd, Dorset, UK), electrophoresed, separated proteins were subsequently transferred onto Trans-Blot Transfer Membrane (Bio-Rad Laboratories Ltd, Hercules, CA, USA). Membranes were blocked by adding $1 \mu \mathrm{g} \mathrm{ml}^{-1}$ anti-FcR Ab (R\&D Systems) to prevent non-specific binding of the primary $A b$, and further incubated with $1 \mu \mathrm{g} \mathrm{ml}^{-1}$ pure mouse anti-human VEGFR-2 Ab (R\&D Systems) overnight at $4{ }^{\circ} \mathrm{C}$. Membranes were washed for $30 \mathrm{~min}$ with Tris Buffered Saline-Tween $1 \%$ and subsequently incubated with $1 \mu \mathrm{g} \mathrm{ml}^{-1}$ of HPR-conjugated anti-mouse $\mathrm{Ab}$ (Cell Signalling, Danvers, MA, USA) for $1 \mathrm{~h}$ at room temperature. Membranes were finally washed with Tris Buffered Saline-Tween $1 \%$ $(4 \times 15$-min washes $)$ and underwent development using ECL analysis system (Amersham Pharmacia Biosciences, Piscataway, NJ, USA), according to the manufacturer's protocol with final exposure to preflashed X-ray film.

\section{Cytotoxicity assay}

The cytotoxic activity of cultured lymphocytes was determined in a standard 4-h ${ }^{51} \mathrm{Cr}$-release assay against K562 (human erythromyeloblastoid leukaemia), Daudi (Burkitt's lymphoma) cell lines and cryopreserved autologous tumour cells from each patients' ascites. Targets $\left(10^{6}\right.$ cells $)$ were labelled with $100 \mu \mathrm{Ci}$ sodium $\left[{ }^{51} \mathrm{Cr}\right]$ chromate (The Radiochemical Centre, Amersham, Bucks, UK) for $1 \mathrm{~h}$ at $37^{\circ} \mathrm{C}$. Effector cells were coincubated with target cells at ratios of $100: 1,50: 1,25: 1$ and $12.5: 1$. After $4 \mathrm{~h}, 100 \mu \mathrm{l}$ of each well's supernatant was removed and isotope was counted in a $\gamma$-counter (1275 Mini-gamma LKB Wallac, Turku, Finland). To determine maximal and spontaneous isotope release, target cells were incubated with $3 \mathrm{~N} \mathrm{HCl}$ and in plain medium, respectively. In all experiments, spontaneous isotope release did not exceed $10 \%$ of maximal release. Percentage of specific cytotoxicity was calculated as described (Ziogas et al, 2012).

\section{Statistical analysis}

Statistical tests were performed using the SPSS software (version 14.0) (IBM, Armonk, NY, USA). Differences in related cell populations at different time points were analysed using the paired Wilcoxon test. Non-parametric Kruskal-Wallis $\mathrm{H}$ and MannWhitney $U$-tests were used to compare medians of cell populations across different time points. All $P$-values were two-sided and $5 \%$ was chosen to denote significance.

\section{RESULTS}

\section{Vascular endothelial growth factor suppresses T-cell proliferation}

Ascites from 15 ovarian cancer patients were used in this study and were selected on the basis of low NK- and B-cell content $(<3-4 \%)$. Mononuclear cells were depleted from monocytes by means of plastic adherence and expanded in cultures with anti-CD3 and IL-2 for 14 days. On day 14 , over $95 \%$ of cells were CD3 positive $(+)$. There was a gradual decrease of $\mathrm{CD} 4+$ cells (and a corresponding increase of CD8 + cells), from a basic mean value of $58.4 \%$ (s.e. 5.2) to $37.7 \%$ (s.e. 7.2$)$ on day $14(P=0.036)$. On day 0 , in all samples the regulatory $\mathrm{T}$-cell subpopulation (Tregs; CD4+ CD25 $\left.5^{\text {high }}\right)$ was low $(<3 \%)$, but significantly increased from a mean value of $0.95 \%$ (s.e. 0.22$)$ to $3.2 \%$ (s.e. 0.59$)(P=0.012)$ by day 14 . CD $3+$ CD56 + cells constituted $\leqslant 6 \%$ of the initial T-cell population and did not show any consistent trend for increase by day 14. Identical changes were also observed in cell cultures exposed in vitro to VEGF, suggesting that these were the result of culture conditions and not due to the effect of this factor.
To investigate whether VEGF could affect the proliferation of $\mathrm{T}$ cells, rVEGF, at concentrations ranging from 0.1 to $100 \mathrm{ng} \mathrm{ml}^{-1}$, was added in cultures at 3- to4-day intervals and cells were counted every 2-3 days until day 14 . Cell proliferation kinetics obtained from three patients during the 14-day period revealed that the most-pronounced VEGF-induced suppression was observed on day 14 (Figure 1A). This was evident at all rVEGF concentrations.

To verify the suppressive effect of rVEGF on T cells, cells from 10 patients were cultured with rVEGF at the same concentrations as above and counted on days 7 and 14 . We observed a dose-dependent inhibitory effect of rVEGF on T-cell expansion, evident both on days 7 (data not shown) and 14 (Figure 1B), where VEGF concentrations $\geqslant 1 \mathrm{ng} \mathrm{ml}^{-1}$ inhibited cell proliferation by $25-50 \%$. Statistically significant differences were noticed between $100 \mathrm{ng} \mathrm{ml}^{-1}$ vs $1,5,10$ and $20 \mathrm{ng} \mathrm{ml}^{-1}$ VEGF $(P<0.05)$, as well as $1 \mathrm{ng} \mathrm{ml}^{-1} v \mathrm{~s}$ higher concentrations. The degree of proliferation inhibition was similar among different T-cell subsets (data not shown).

\section{Activated T cells express VEGFR-2}

To detect the expression of different types of VEGFR on anti-CD3 and IL-2-activated T cells, lymphocytes from five patients were analysed for the expression of VEGFR-1, -2 and -3 by means of flow cytometry, immunocytochemistry and western blotting. Although VEGFR-1 or -3 were not expressed (data not shown), VEGFR-2 was detected on the surface of $\mathrm{CD}^{+}{ }^{+} \mathrm{T}$ cells (Figure 2A). More specifically, on day $0,<5 \%$ of the cells expressed VEGFR-2,
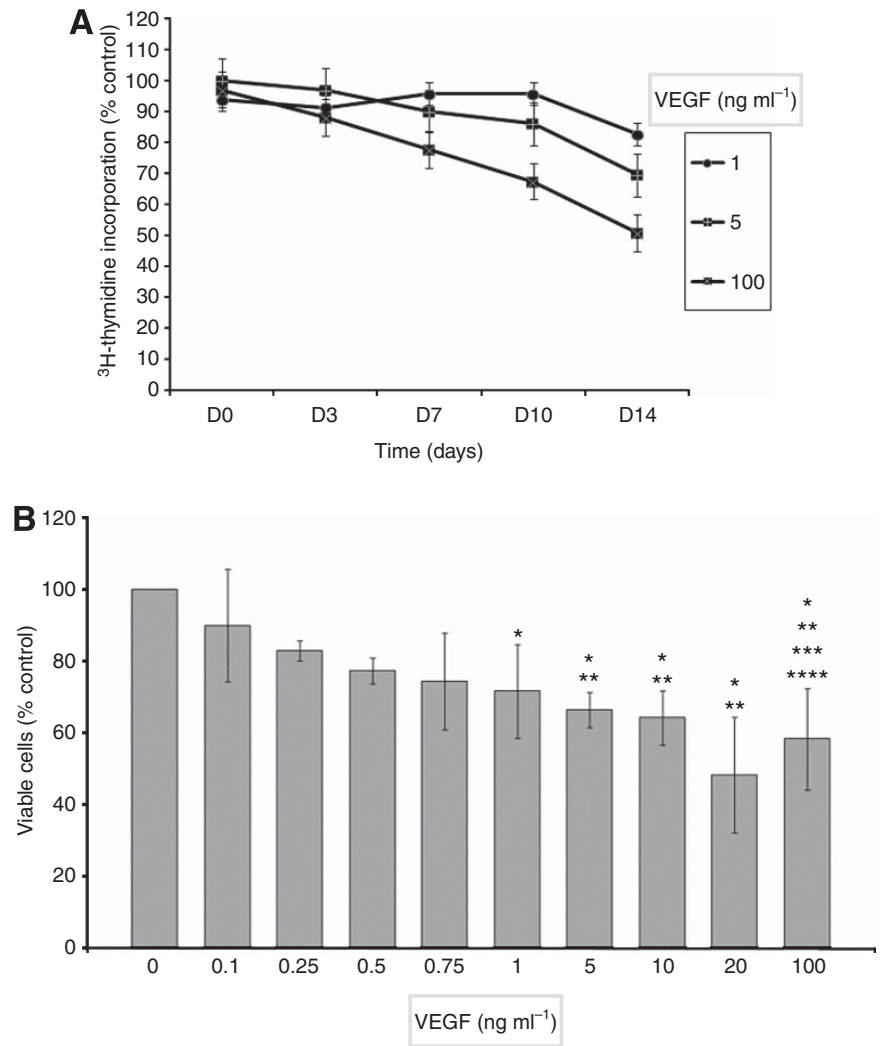

Figure I Vascular endothelial growth factor suppresses ascites-derived T-cell proliferation. (A) Time kinetics (0-14 days) of VEGF-induced $\left(0.1-100 \mathrm{ng} \mathrm{ml}^{-1}\right)$ reduction of $\mathrm{T}$-cell proliferation, as assessed via ${ }^{3} \mathrm{H}$ thymidine incorporation assay. Pooled data from three cancer patients are shown. (B) Dose-dependent (0.1-100 $\left.\mathrm{ng} \mathrm{ml}^{-1}\right)$ VEGF-induced inhibition of T-cell expansion. Cell growth was measured at day |4. Pooled data $(n=15)$ are shown. Asterisks denote statistically significant differences $(P<0.05)$ compared with control (*), I ng ml ${ }^{-1}(* *), 5 \mathrm{ng} \mathrm{ml}^{-1}$ (***) and $10 \mathrm{ng} \mathrm{ml}^{-1}$ (*****). 

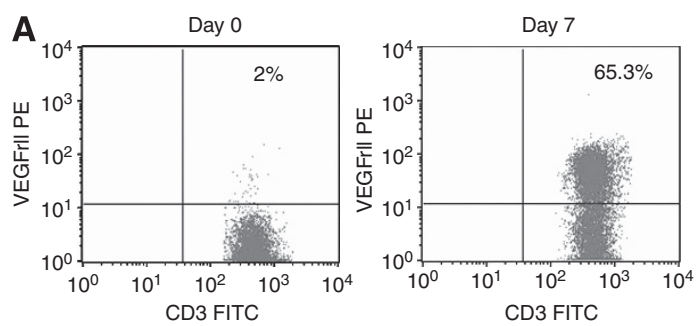

B
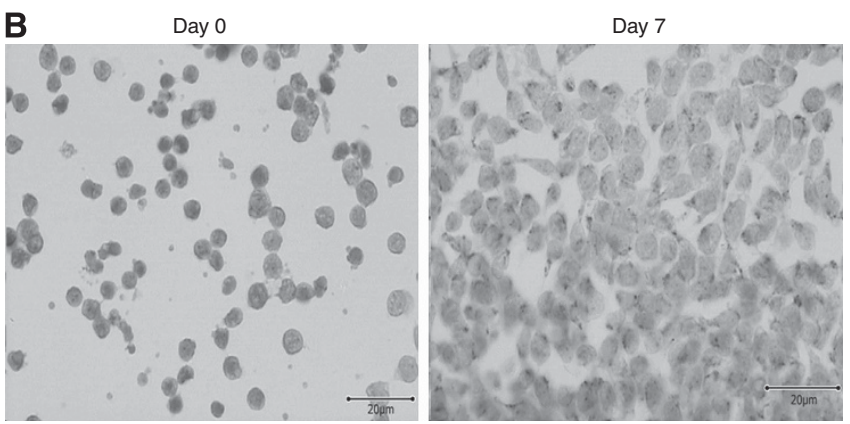

C

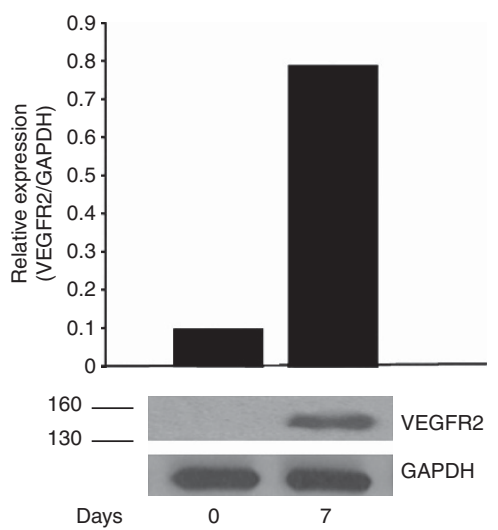

Figure 2 Activated T cells express VEGFR-2. (A) Flow cytometry results showing a representative experiment of $T$ cells from an ovarian cancer patient's ascites cultured with anti-CD3 and IL-2 for 7 days. Analysis was performed on gated $\mathrm{CD}^{+}$cells. Increased expression of VEGFR-2 is observed. (B) Immunocytochemistry images showing increased surface expression of VEGFR-2 (brown colour) on day 7 compared with day 0 (negative). (C) Western blot of ascites-derived T cells, expressing VEGFR-2 are shown. Cells were cultured with IL-2 and anti-CD3 antibody, with or without adding VEGF (see Materials and Methods). Cells were collected at 0 and 7 days of culture. Vascular endothelial growth factor receptor- 2 was detected at 7 days. GAPDH was used as a loading control. Densitometry is illustrated above the blot. The illustrated blot is a representative of three experiments performed with similar results. The color reproduction of this figure is available on the British Journal of Cancer online.

whereas on day 7 the percentage of cultured $\mathrm{T}$ cells expressing VEGFR-2 was highly increased to $61-87 \%$. Vascular endothelial growth factor receptor-2 was expressed irrespective of the presence of rVEGF at any concentration in lymphocyte cultures, indicating that its expression was the result of T-cell activation and was not induced by VEGF. Vascular endothelial growth factor receptor-2 expression did not correlate with any specific T-cell subpopulation. These data were further confirmed by immunocytochemistry and western blot analysis (Figure $2 \mathrm{~B}$ and $\mathrm{C}$ ).

\section{Vascular endothelial growth factor suppresses T-cell proliferation through VEGFR-2}

To determine whether VEGF-induced suppression of activated T-cell proliferation was mediated through ligation of VEGF to

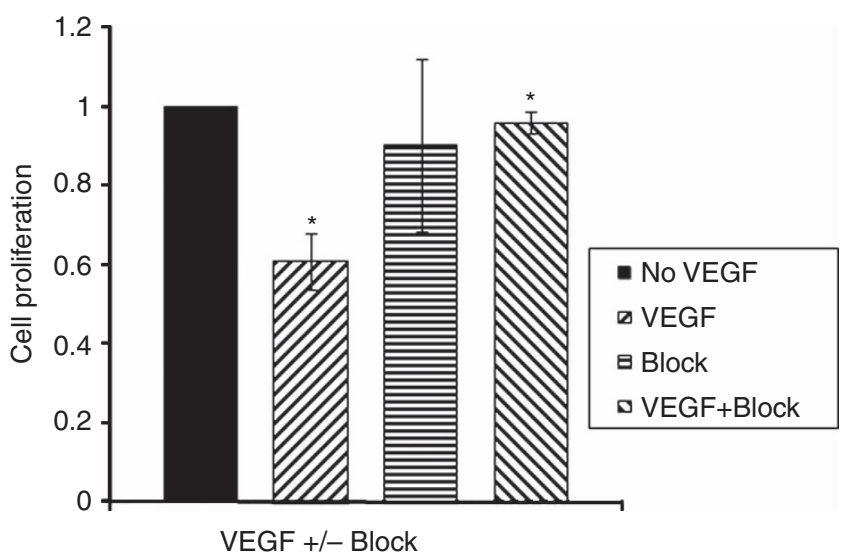

Figure 3 Anti-VEGFR-2 reverses VEGF-induced suppression of $T$ cells. Neutralising anti-VEGFR-2 mAb (block) was added in lymphocyte cultures $(n=5)$ at a final concentration of $\mid \mu \mathrm{g} \mathrm{ml}^{-1}$ for 14 days in the presence of VEGF $\left(100 \mathrm{ng} \mathrm{ml}^{-1}\right)$. $* P=0.043$ compared with control.

VEGFR-2, neutralising anti-VEGFR-2 mAb was added in the lymphocyte cultures of five patients, at a final concentration of $1 \mu \mathrm{g} \mathrm{ml}^{-1}$. The addition of anti-VEGFR-2 mAb fully restored T-cell expansion, even when these $\mathrm{T}$ cells were cultured in the presence of the highest rVEGF concentration used $\left(100 \mathrm{ng} \mathrm{ml}^{-1}\right.$ ) (Figure 3). These results indicate that the suppressive activity of VEGF on T cells is exerted through VEGFR-2, expressed upon their activation.

\section{Vascular endothelial growth factor is secreted by activated $\mathrm{T}$ cells}

To investigate whether activated $\mathrm{T}$ cells secrete VEGF, $\mathrm{T}$ cells from three patients were expanded in cultures with anti-CD3 and IL-2 for 14 days and VEGF levels in culture supernatants were measured by ELISA at 7 and 14 days. There was a reduction in the amount of soluble VEGF from day 7 to day 14 (mean values: 535 (s.e. 439) vs 194 (s.e. 95) $\mathrm{pg} \mathrm{ml}^{-1}, P=0.467$ ), indicating that activated $T$ cells have the ability to secrete VEGF in their culture environment. It should be noted that the mean VEGF value in the ascites of the same patients was $1873 \mathrm{pg} \mathrm{ml}^{-1}$ and these high ascitic VEGF levels did not correlate with the amount of VEGF determined in T-cell culture supernatants $(P=0.299$ and $P=0.117$, for days 7 and 14 , respectively).

\section{Vascular endothelial growth factor reduces the cytotoxic activity of $\mathrm{T}$ cells}

To assess the dose-dependent effect of VEGF on T-cell cytotoxicity, various concentrations of rVEGF $\left(0.1-100 \mathrm{ng} \mathrm{ml}^{-1}\right)$ were repeatedly added to T-cell cultures from the ascites of five ovarian cancer patients over 14 days. For statistical analyses, data from all effector:target ratios at each concentrations were pooled together. On the day of culture initiation, isolated lymphocytes exhibited marginal cell lysis $(\leqslant 10 \%)$. Low VEGF concentrations did not reduce T-cell cytotoxicity on days 7 and 14, whereas VEGF concentrations $\geqslant 1 \mathrm{ng} \mathrm{ml}^{-1}$ considerably inhibited T-cellmediated target cell lysis at all effector to target cell ratios tested (Figure 4). Specifically, statistically significant decrease of T-cell cytotoxicity was noticed by $1-100 \mathrm{ng}^{\mathrm{VEGF} \mathrm{ml}}{ }^{-1}$ against $\mathrm{K} 562$ and Daudi (in all cases, $P=0.012$ ) and by $5-100 \mathrm{ng} \mathrm{VEGF} \mathrm{ml}^{-1}$ against autologous cancer cells $(P=0.018)$. The reduction of target cell lysis was most prominent on day 14 , indicating that both the concentration and the prolonged presence of VEGF contribute to T-cell cytotoxic activity suppression. The cytotoxicity against 


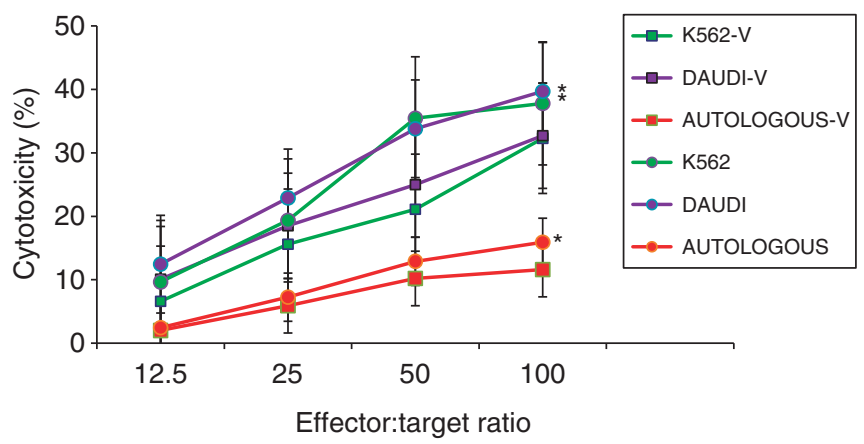

Figure 4 Vascular endothelial growth factor suppresses T-cell cytotoxicity. Lymphocytes from the ascites of five ovarian cancer patients were incubated for 14 days with anti-CD3 and IL-2 in the absence or presence of VEGF $5 \mathrm{ng} \mathrm{ml}^{-1}$ and tested against K562, Daudi and autologous cancer cells targets at various effector to target ratios. Data are presented as mean values \pm s.d. $* P<0.05$ for comparison between control and VEGF-exposed cells. Statistical analysis was performed on pooled data from all effector:target ratios.

autologous cancer cells was lower than against the other two targets $(P=0.012)$ for controls and VEGF-treated cells.

\section{DISCUSSION}

In cancer patients, immune system functions are impaired. Tumours have effectively developed several mechanisms of escaping immune surveillance. These include the production of immunosuppressive factors, comprising cytokines, such as TGFbeta and IL-10, which act directly or indirectly on T cells and/or monocytes (Zou, 2005). Solid tumours are known to also produce abundant amounts of VEGF, which besides promoting the extension of tumour vasculature, has been shown to hinder dendritic cell functional maturation, a key element for tumour antigen-specific activation of T cells (Gabrilovich et al, 1996). Our group has previously shown that in patients with advanced ovarian cancer, VEGF levels in ascites were inversely correlated with specific T-cell subpopulations, which are essential for mounting an effective antitumor response (Bamias et al, 2008). Considering the relatively high concentration of VEGF in the ascitic fluid of these patients, we considered that VEGF may exert its inhibitory effect directly on $\mathrm{T}$ cells through VEGF receptors expressed on their surface, an effect that results in suppression of their proliferation, thus having a significant role in tumour escape from immune surveillance.

Vascular endothelial growth factor receptor mRNA expression in mouse and human T-cell lines as well as in blood lymphocytes from cancer patients has been previously reported (Freeman et al, 1995; Mor et al, 2004; Suzuki et al, 2010). To our knowledge, this is the first study demonstrating a significant inhibitory effect of VEGF, through VEGFR-2, on the proliferation of $\mathrm{T}$ cells derived from ascites of ovarian cancer patients. This effect was time- and dose-dependent and exerted at VEGF concentrations usually found in ascites, rather than in the serum in the clinical setting. We report that anti-CD3 and IL-2 induce the expression of VEGFR-2 on the surface of T cells and this was not dependent on the presence of VEGF in culture. This phenomenon was not limited to any specific T-cell subpopulation. It should be pointed out that the small percentage of immunologically important populations, such as Tregs or $\mathrm{CD} 3+\mathrm{CD} 56+$ cells, may have prevented the detection of mild changes in our experiments. In concert to our results, Basu et al (2010) reported no VEGFR expression on unactivated peripheral blood T cells. Nevertheless, upon activation they expressed both VEGFR-1 and -2. As in our previous findings (Ziogas et al, 2012), we did not find VEGFR-1 expression, which supports the notion that the main effects of VEGF are mediated through binding to VEGFR-2. This difference with the findings of Basu et al (2010) could be attributed to the different T-cell types used in this study, that is, $\mathrm{T}$ cells derived from ascites rather than blood, but also due to the T-cell activation protocols used by Basu et al (2010) and herein $(24 \mathrm{~h}$ with $1 \mu \mathrm{g} \mathrm{ml}^{-1}$ anti-CD3 vs 7-14 days with $25 \mathrm{ng} \mathrm{ml}^{-1}$ anti-CD3 and IL-2, respectively). Most importantly, as Basu et al (2010) studied VEGFR expression on antigen-experienced memory $\left(\mathrm{CD} 4{ }^{+} \mathrm{CD} 4 \mathrm{RO}^{+}\right) \mathrm{T}$ cells, a possibility to be considered is a differential expression pattern of VEGFRs among selected T-cell subsets, correlated with subsequent cell activation or suppression via pleiotropically acting cytokines as VEGF.

Vascular endothelial growth factor exhibited a functional inhibitory effect on $\mathrm{T}$ lymphocytes. This was evident against K562, Daudi and autologous cell targets. The minimal VEGF concentration (1-5 $\mathrm{ng} \mathrm{ml}^{-1}$ ), which suppressed T-cell proliferation and function, is in line with the levels of VEGF measured in the ascites of ovarian cancer patients (Bamias et al, 2008). The clinical relevance of our findings is further enhanced by the fact that, as already reported by our team, VEGF concentration $>1.9 \mathrm{ng} \mathrm{ml}^{-1}$ in ascites was associated with adverse prognosis (Bamias et al, 2008).

The capacity of $\mathrm{T}$ cells to lyse autologous cancer cells was low compared with that against K562 and Daudi and was further reduced by VEGF. Several reasons can justify this observation. First, in our culture system, the presence of anti-CD3 in conjunction with IL-2 in the absence of antigenic stimulus, favours the non-specific activation of all cells bearing T-cell receptors. Consequently, autologous tumour antigen-specific $\mathrm{T}$-cell clones are not preferentially expanded and may finally comprise a minor subpopulation among proliferating $\mathrm{T}$ cells (Crossland et al, 1991). Second, the suppressive milieu of the ascites is likely to hinder the functionalities particularly of tumour antigen-specific $\mathrm{T}$ cells, resulting in their poor propagation ex vivo (Ioannides et al, 1991). Finally, autologous tumour cells are often reported to escape T-cell-mediated killing by downregulating $\mathrm{MHC}$ molecule and/or tumour antigen expression (Igney and Krammer, 2002). Therefore, the fact that we observed killing of autologous cells is significant by itself. This, viewed in the context of our other findings, supports the hypothesis that $\mathrm{T}$ cells residing in an environment rich in tumour cells, are initially activated by tumour-associated antigens, but this activation leads to VEGFR-2 expression and finally to suppression, induced by the increased VEGF levels present within ascitic fluids. It is also of importance to stress here, that the action of $\mathrm{T}$ cells against autologous cancer cells is a major feature of this study compared with our previous paper (Ziogas et al, 2012).

We and others have previously shown that secretion of VEGF by peripheral blood T cells can be induced by IL-2 and anti-CD3 (Zou, 2005; Mikko et al, 2009; Shin et al, 2009; Ziogas et al, 2012). In this paper, we further demonstrate for the first time that anti-CD3 and IL-2, apart from their mitogenic effect, induce VEGF secretion from ascites-derived $\mathrm{T}$ cells as well. These findings may have implications for the physiology and pathophysiology of the immunological anti-tumour response, tumour angiogenesis and, eventually, tumour escape. It is generally accepted that an effective anti-tumour response includes primarily the recognition of tumour antigens by $\mathrm{T}$ cells, the subsequent activation of $\mathrm{T}$ cells through the T-cell receptor (this process can be mimicked by stimulating $\mathrm{T}$ cells with anti-CD3), and the release of immunostimulatory factors from immune cells, such as IL-2, which sustains T-cell proliferation. As this study shows, such immunological processes induce the synthesis of VEGF. This event may suggest that T-cell-derived VEGF could promote tumour angiogenesis as a result of a paracrine interaction with the tumour stroma. Activated $\mathrm{T}$ cells induce the expression of VEGFR-2 on their surface, thus 
becoming susceptible to suppression by VEGF. The levels of VEGF produced in culture were higher than those we previously found by $\mathrm{T}$ cells isolated from peripheral blood of patients with ovarian cancer (Ziogas et al, 2012). This, taken together with the dosedependent effect of VEGF, indicates that the autocrine effect is more prominent within the tumour environment. Nevertheless, the levels necessary to induce suppression of proliferation and function of $\mathrm{T}$ cells in culture, were much higher than those produced by $\mathrm{T}$ cells. On the contrary, suppressive VEGF levels were similar to those measured in the ascites in this study as well as in our previous larger cohort of advanced ovarian cancer patients (Bamias et al, 2008). We, therefore, believe that endogenous VEGF is not the major cause of T-cell suppression, at least in ovarian cancer, which should be mainly attributed to tumour-derived VEGF. The autocrine effect could have a significant role in the regulation of uncontrolled activation of $\mathrm{T}$ cells in several physiological or pathological conditions, such as in inflammation or autoimmunity.

\section{REFERENCES}

Bamias A, Koutsoukou V, Terpos E, Tsiatas ML, Liakos C, Tsitsilonis O, Rodolakis A, Voulgaris Z, Vlahos G, Papageorgiou T, Papatheodoridis G, Archimandritis A, Antsaklis A, Dimopoulos MA (2008) Correlation of NK T-like CD3 + CD56 + cells and CD4 + CD25 + (hi) regulatory T cells with VEGF and TNFalpha in ascites from advanced ovarian cancer: Association with platinum resistance and prognosis in patients receiving first-line, platinum-based chemotherapy. Gynecol Oncol 108: 421-427

Bamias A, Tsiatas ML, Kafantari E, Liakou C, Rodolakis A, Voulgaris Z, Vlahos G, Papageorgiou T, Tsitsilonis O, Bamia C, Papatheodoridis G, Politi E, Archimandritis A, Antsaklis A, Dimopoulos MA (2007) Significant differences of lymphocytes isolated from ascites of patients with ovarian cancer compared to blood and tumor lymphocytes. Association of $\mathrm{CD} 3+\mathrm{CD} 56+$ cells with platinum resistance. Gynecol Oncol 106: 75-81

Basu A, Hoerning A, Datta D, Edelbauer M, Stack MP, Calzadilla K, Pal S, Briscoe DM (2010) Cutting edge: vascular endothelial growth factormediated signaling in human CD45RO + CD4 $+\mathrm{T}$ cells promotes Akt and ERK activation and costimulates IFN-gamma production. $J$ Immunol 184: 545-549

Bergers G, Benjamin LE (2003) Tumorigenesis and the angiogenic switch. Nat Rev Cancer 3: 401-410

Burger RA, Brady MF, Bookman MA, Walker JL, Homesley HD, Fowler J, Monk BJ, Greer BE, Boente M, Liang SX (2010) Phase III trial of bevacizumab (BEV) in the primary treatment of advanced epithelial ovarian cancer (EOC), primary peritoneal cancer (PPC), or Fallopian tube cancer (FTC): A Gynecologic Oncology Group study. J Clin Oncol 28(Suppl_LBA1): $18 \mathrm{~s}$

Crossland KD, Lee VK, Chen W, Riddel SR, Greenberg PD, Cheever MA (1991) $\mathrm{T}$ cells from tumor immune mice nonspecifically expanded in vitro with anti CD3 plus IL-2 retain specific function in vitro and can eradicate disseminated leukemia in vivo. I Immunol 146: 4414-4420

Ferrara N (2004) Vascular endothelial growth factor: basic science and clinical progress. Endocr Rev 25: 581-611

Freeman MR, Schneck FX, Gagnon ML, Corless C, Soker S, Niknejad K, Peoples GE, Klagsbrun M (1995) Peripheral blood T lymphocytes and lymphocytes infiltrating human cancers express vascular endothelial growth factor: a potential role for T cells in angiogenesis. Cancer Res 55: 4140-4415

Gabrilovich DI, Chen HL, Girgis KR, Cunningham HT, Meny GM, Nadaf S, Kavanaugh D, Carbone DP (1996) Production of vascular endothelial growth factor by human tumors inhibits the functional maturation of dendritic cells. Nat Med 2: 1096-1103

Gasparini G, Longo R, Toi M, Ferrara N (2005) Angiogenic inhibitors: a new therapeutic strategy in oncology. Nat Clin Pract Oncol 2: 562-577

Georgaki S, Skopeliti M, Tsiatas M, Nicolaou KA, Ioannou K, Husband A, Bamias A, Dimopoulos MA, Constantinou AI, Tsitsilonis OE (2009) Phenoxodiol, an anticancer isoflavene, induces immunomodulatory effects in vitro and in vivo. J Cell Mol Med 13: 3929-3938

Hicklin DJ, Ellis LM (2005) Role of the vascular endothelial growth factor pathway in tumor growth and angiogenesis. J Clin Oncol 23: 1011-1027
In summary, we have demonstrated for the first time that T lymphocytes derived from ovarian cancer patients' ascites secrete VEGF and express VEGFR-2 on their surface in response to their activation. This in turn, promotes the suppression of activated $\mathrm{T}$ cells by the VEGF produced by the tumour, thus suggesting an immunosuppressive effect. These findings may have clinical relevance, particularly after recent results suggesting a benefit by the addition of the anti-VEGF monoclonal antibody, bevacizumab, to chemotherapy for advanced ovarian cancer (Burger and Brady, 2010; Markman, 2011). The rationale is that anti-VEGF and/or VEGFR-2 therapies may target not only angiogenesis but also tumor escape from immune surveillance. If this is true, the degree of the effect of VEGF on the immune system may be used to select patients likely to benefit from such approaches.

Supplementary Information accompanies the paper on British Journal of Cancer website (http://www.nature.com/bjc)
Igney FH, Krammer PH (2002) Immune escape of tumors: apoptosis resistance and tumor counterattack. J Leucoc Biol 71: 907-920

Ioannides CG, Platsoucas CD, Rashed S, Wharton JT, Edwards CL, Freedman RS (1991) Tumor cytolysis by lymphocytes infiltrating ovarian malignant ascites. Cancer Res 51: 4257-4265

Lyons III JM, Schwimer JE, Anthony CT, Thomson JL, Cundiff JD, Casey DT, Maccini C, Kucera P, Wang YZ, Boudreaux JP, Woltering EA (2010) The role of VEGF pathways in human physiologic and pathologic angiogenesis. J Surg Res 159: 517-527

Markman M (2012) Addition of bevacizumab to weekly paclitaxel significantly improves progression-free survival in heavily pretreated recurrent epithelial ovarian cancer. Gyneacol Oncol 124: 171

Mikko M, Wahlström J, Grunewald J, Magnus Sköld C (2009) Hypoxia but not cigarette smoke modulates VEGF secretion from human $\mathrm{T}$ cells. Growth Factors 27: 352-361

Mimura K, Kono K, Takahashi A, Kawaguchi Y, Fujii H (2007) Vascular endothelial growth factor inhibits the function of human mature dendritic cells mediated by VEGF receptor-2. Cancer Immunol Immunother 56: 761-770

Mor F, Quintana FJ, Cohen IR (2004) Angiogenesis-inflammation crosstalk: vascular endothelial growth factor is secreted by activated $\mathrm{T}$ cells and induces Th1 polarization. J Immunol 172: 4618-4623

Ohm JE, Gabrilovich DI, Sempowski GD, Kisseleva E, Parman KS, Nadaf S, Carbone DP (2003) Vegf inhibits T-cell development and may contribute to tumor-induced immune suppression. Blood 101: 4878-4886

Ribatti D, Vacca A (2008) The role of microenvironment in tumor angiogenesis. Genes Nutr 3: 29-34

Sambrook J, Fritsch EF, Maniatis T (1989) Molecular Cloning: A Laboratory Manual. 2nd edn, pp 2324-2316. Cold Spring Harbor Laboratory Press: Cold Spring Harbor, NY

Shin JY, Yoon IH, Kim JS, Kim B, Park CG (2009) Vascular endothelial growth factor-induced chemotaxis and IL-10 from T cells. Cell Immunol 256: $72-78$

Suzuki H, Onishi H, Wada J, Yamasaki A, Tanaka H, Nakano K, Morisaki T, Katano M (2010) VEGFR2 is selectively expressed by FOXP3high CD4+ Treg. Eur J Immunol 40: 197-203

Tam BY, Wei K, Rudge JS, Hoffman J, Holash J, Park SK, Yuan J, Hefner C, Chartier C, Lee JS, Jiang S, Nayak NR, Kuypers FA, Ma L, Sundram U, Wu G, Garcia JA, Schrier SL, Maher JJ, Johnson RS, Yancopoulos GD, Mulligan RC, Kuo CJ (2006) VEGF modulates erythropoiesis through regulation of adult hepatic erythropoietin synthesis. Nat Med 12: 793-800

Waldner MJ, Wirtz S, Jefremow A, Warntjen M, Neufert C, Atreya R, Becker C, Weigmann B, Vieth M, Rose-John S, Neurath MF (2010) VEGF receptor signaling links inflammation and tumorigenesis in colitisassociated cancer. J Exp Med 207: 2855-2868

Zindl CL, Chaplin DD (2010) Immunology. Tumor immune evasion. Science 328: 697-698

Ziogas AC, Gavalas NG, Tsiatas M, Tsitsilonis O, Politi E, Terpos E, Rodolakis A, Vlahos G, Thomakos N, Haidopoulos D, Antsaklis A, 
Dimopoulos MA, Bamias A (2012) VEGF directly suppresses activation of $\mathrm{T}$ cells from ovarian cancer patients and healthy individuals via VEGF receptor Type 2. Int J Cancer 130: 857-864

Zou W (2005) Immunosuppressive networks in the tumour environment and their therapeutic relevance. Nat Rev Cancer 5: 263-274
Zucker S, Mirza H, Conner CE, Lorenz AF, Drews MH, Bahou WF, Jesty J (1998) Vascular endothelial growth factor induces tissue factor and matrix metalloproteinase production in endothelial cells: conversion of prothrombin to thrombin results in progelatinase $\mathrm{A}$ activation and cell proliferation. Int J Cancer 75: 780-786

This work is published under the standard license to publish agreement. After 12 months the work will become freely available and the license terms will switch to a Creative Commons Attribution-NonCommercial-Share Alike 3.0 Unported License. 